\title{
A rapid and sensitive culture test for the laboratory diagnosis of genital herpes in women
}

\author{
S DAROUGAR,* P WALPITA,* U THAKER,* B T GOH, $\dagger$ AND E M C DUNLOP $\dagger$ \\ From the *Subdepartment of Virology, Institute of Ophthalmology, University of London, and the $†$ Whitechapel \\ Clinic, The London Hospital, London
}

SUMMARY A rapid and sensitive cell culture test has been developed to detect herpes simplex virus (HSV) in women with genital herpes. The virus is cultured by inoculation and centrifugation of cell monolayers, and the virus inclusions are detected using an indirect immunofluorescence test. The test takes only 48 hours to complete compared with the conventional cell culture test, which may take up to eight days. Of a total of 2100 cervical specimens collected from unselected women attending a sexually transmitted diseases (STD) clinic and inoculated in parallel, HSV was isolated from 55 specimens by either or both tests. Of these 55 positive specimens, $54(98 \%)$ were positive by the rapid test but only $24(44 \%)$ by the conventional test (McNemars test; $p<0.001$ ).

\section{Introduction}

The prevalence of genital infection with herpes simplex virus (HSV) has been increasing rapidly over the last decade and HSV is now considered to be the commonest cause of genital ulcerations in the developed world. ${ }^{1-3}$ Data available for the United Kingdom suggest a yearly increase of about $11 \%$ in the incidence of genital HSV infections. This is a greater increase than that of any other sexually transmitted disease (STD). ${ }^{4}$ The clinical manifestations of genital infection with HSV in women are often few, absent, or atypical and overlap those of other infections. ${ }^{5}$ In view of the potentially serious consequences of genital infection with HSV and because control of symptoms is now possible, laboratory tests that are rapid, simple, and sensitive are a major help in diagnosis. The conventional cell culture method for virus isolation, which relies on the development of cytopathic effect, provides the most sensitive and specific diagnostic method, ${ }^{5}$ but it is relatively slow. Staining exfoliated cells and detecting antigen are generally less sensitive than virus isolation methods. ${ }^{6-8} \mathrm{HSV}$ serological tests are the least sensitive of the available methods, even using paired serum samples. ${ }^{5}$

We have developed a cell culture test that is more sensitive than the conventional cell culture method for $\mathrm{HSV}$ isolation and requires only two days to complete.

Address for reprints: Professor S Darougar, Subdepartment of Virology, Institute of Ophthalmology, University of London, Judd Street. London WCIH 9QS

Accepted for publication 21 July 1985

\section{Patients, materials, and methods}

\section{SPECIMENS}

We collected cervical swabs from an unselected group of women who presented to an STD clinic in London during about six months. The specimens were collected in plastic vials containing glass beads and 2SP transport medium with antibiotics. ${ }^{9}$ They were transported to the laboratory in liquid nitrogen and stored at $-70^{\circ} \mathrm{C}$ until inoculated.

\section{TISSUE CULTURE AND INOCULATION}

We prepared HEp2 cell monolayers in test tubes and on $13 \mathrm{~mm}$ coverslips in flat bottomed tubes by seeding each tube with $1 \mathrm{ml}$ of growth medium containing 25000 to 30000 cells $/ \mathrm{ml}$ and incubating at $35^{\circ} \mathrm{C}$ for 48 hours. The growth medium consisted of Eagle's minimum essential medium supplemented with vitamins, glutamine, penicillin $(110 \mathrm{IU} / \mathrm{ml})$, streptomycin $(50 \mathrm{mg} / \mathrm{l})$, and $10 \%$ fetal bovine serum. After 48 hours, when the monolayers were about $80 \%$ confluent, the growth medium was replaced with maintenance medium containing $3 \%$ fetal bovine serum.

All specimens were whirlmixed, and equal aliquots of each were inoculated in one test tube and one flat bottomed tube. A positive and negative control were set up with each batch of tests.

\section{RAPID TEST}

The inoculated flat bottomed tubes were centrifuged at $15000 \times g$ for one hour and then incubated at $35^{\circ} \mathrm{C}$ for 48 hours. At the end of this period, the coverslips were fixed with methanol for 15 minutes and stained using an indirect immunofluorescence method. Table I compares the individual steps of the two tests. 
TABII: 1 Steps of rapid culture test compared with conventional cell culture test

\begin{tabular}{ll}
\hline Rapid culture test & Conventional cell culture test \\
\hline 1. Cell monolayer on coverslip in flat bottomed tubes & Cell monolayer in test tube \\
2. Inoculation & Inoculation \\
3. Incubation (2 days) & Incubation (up to 8 days) \\
4. Immunofluorescence staining & Examination for cytopathic effect \\
& Virus identification by immunofluorescence staining of smears from \\
& test tubes that show a cytopathic effect \\
\hline
\end{tabular}

\section{IMMUNOFLUORESCENCE STAINING METHOD}

Group specific antiserum to HSV was raised in rabbits in our laboratory, and the anti-rabbit fluorescein conjugate was obtained from Burroughs Wellcome London. Each new batch of serum samples was titrated to obtain the optimum working dilution. The fixed coverslips were mounted on a staining frame. A drop of the appropriately diluted antiserum to HSV was placed on each of the coverslips, spread with a loop, and incubated in a moist chamber for 30 minutes. The coverslips were washed in phosphate buffered saline for 15 minutes using a magnetic stirrer, air dried, and then covered with a drop of the fluorescein conjugated anti-rabbit serum. The incubation and washing steps were repeated as before. The coverslips were finally washed for five minutes in distilled water before being dried and mounted. ${ }^{10}$

The criterion for positivity was the finding of one or more intracellular granular inclusions that fluoresced bright green.

\section{CONVENTIONAL TEST}

After being inoculated, the test tubes were incubated at $35^{\circ} \mathrm{C}$ on roller drums and examined daily or every other day for a cytopathic effect. Smears were made from test tubes showing a cytopathic effect, and the virus was identified by an indirect immunofluorescence test. Table I shows the individual steps of the test.

\section{Results}

Table II gives a detailed analysis of the comparative

TABLI II Comparative sensitivity and correlation of positivit! between the rapid and the conventional cell culture tests for herpes simplex virus

\begin{tabular}{ll}
\hline Results of the paired tests & Vo ('i) positive \\
\hline Positive by either or both tests & $55(100)$ \\
Positive by rapid test & $54(98 \cdot 2)$ \\
Positive by conventional test & $24(43 \cdot 6)$ \\
Positive by both tests & $23(41 \cdot 8)$ \\
Positive by rapid test only & $31(56 \cdot 3)$ \\
Positive by conventional test only & $1(1 \cdot 8)$ \\
\hline
\end{tabular}

McNemars test (rapid test 1 conventional test): $U=5 \cdot 65, p<0 \cdot 001$. sensitivity and a correlation of the positivity of the two methods. Of 2100 cervical specimens inoculated in parallel by the rapid and the conventional cell culture tests, HSV was isolated by either or both tests from a total of 55 specimens. Of these, $54(98 \%)$ were positive by the rapid test but only $24(44 \%)$ by the conventional test, a significant difference (McNemars test; $\mathrm{p}<0.0001$ ).

Table III shows that a cytopathic effect took one to eight days to develop using the conventional test and $26 \%$ of specimens took between five and eight days to develop a cytopathic effect.

\section{Discussion}

The rapid test described here is simple to perform and takes only 48 hours to complete. It is appreciably more sensitive than the conventional test in detecting HSV from genital specimens.

HSV replicates well in a number of different types of cells, but most laboratories use human embryo fibroblast cell lines, such as WI-38 or MRC-5. In this study we used HEp2 cells, which appear to have a sensitivity comparable with that of human embryo lung cells for HSV isolation."

It is widely believed that HSV grows rapidly in conventional cell culture test and that most positive specimens show a cytopathic effect within 48 hours. There is little published evidence, however, to support this belief. In a study by Moore, in which a large proportion of the specimens were collected from vesicular lesions and had an expectedly high virus titre, only $72 \%$ of the HSV positive results were detectable in 48 hours. Similarly, in this laboratory, in

TABLE III Day of first appearance of cltopathic effect in 23 cultures positive for herpes simplex virus by the conventional test

\begin{tabular}{ll} 
Dat of first appearance & No*(') of specimens showing \\
of crtopathic effect & crtopathic effect \\
\hline $1-2$ & $4(17 \cdot 4)$ \\
$3-4$ & $13(56 \cdot 5)$ \\
$5-8$ & $6(26 \cdot 1)$ \\
\hline
\end{tabular}

* Information was not available in one case.

Mean (SD) $3.9(1.84)$ days. range $1-8$ days. 
a study of 95 women with a provisional clinical diagnosis of HSV infection, only $71 \%$ of the positive results were identified at 48 hours (unpublished data). Results of tests on the specimens from unselected women presented here (table III) showed that only $8.3 \%$ of the HSV isolates were detected at 48 hours, $26 \%$ took between five and eight days, and the mean time taken to develop a cytopathic effect was 3.9 days.

In the rapid test, a 48 hour incubation period was chosen because, in a pilot study, we found no difference in HSV detection rates between 48 and 72 hour incubation periods. The sensitivity of the rapid test after incubation for 24 hours was slightly less than than after 48 hours.

In the conventional test the cell cultures are traditionally examined for a cytopathic effect for up to 21 days (three weekly passages). In this study we incubated the cultures for eight days (one passage). In our experience, incubation beyond this period yields only a small proportion (about 3\%) of additional positive results for HSV in specimens from the genital tract (unpublished data).

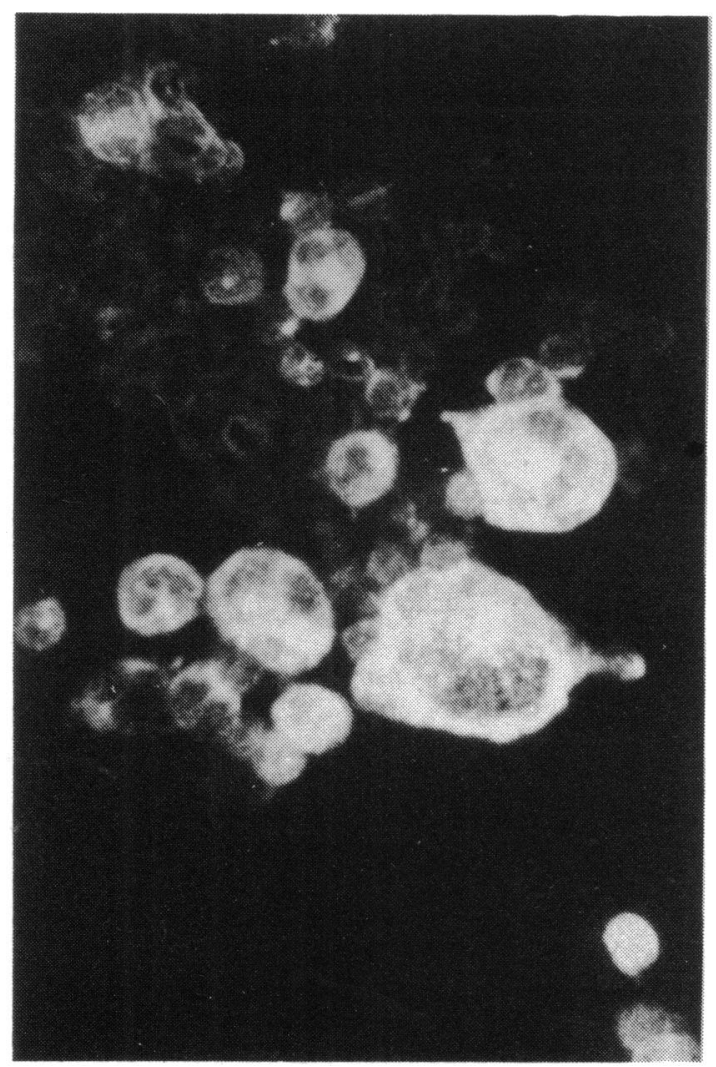

FIGURE Bright, granular, and intracellular herpes simplex virus inclusions stained $b y$ an indirect immunofluorescence method (540 $\times$ magnification).
The rabbit antibody to HSV used in this study was found to be entirely satisfactory. The antisera used for the staining were checked for specificity, and each new batch was titrated to obtain the optimum working dilution. The background staining was minimal, and there was a distinct difference in the staining reactions of the infected and the non-infected cells (figure). The positive cultures produced brightly fluorescing, granular, and intracellular inclusions. Such inclusions were not found in the negative control cultures. Our previous work has shown that when the strict criteria of culture, staining, and recognition of inclusions are used, the finding of even one such inclusion is adequate for a positive diagnosis; the chances of a false positive result using the rapid test are remote.

The greater sensitivity of the rapid test is probably largely a reflection of its ability to detect HSV from cases of mild infection. Some $50 \%$ of women studied here had no clinical evidence of HSV infection. In such patients, the virus titre is generally expected to be low. Centrifuging the inoculated monolayer has been shown to increase the HSV isolation rate compared with the conventional test. ${ }^{13}$ Centrifuging may possibly increase contact and penetration of the virus on to the monolayer, thus increasing the chances of picking up virus from these low titred specimens.

Bacterial or fungal contamination of the genital specimens occasionally destroys the cell monolayer in the conventional method. We found that such contamination of the monolayer usually did not interfere with the easy detection of HSV inclusions in the rapid test. This could also be a factor in the greater sensitivity of the rapid test.

The rapid test we describe here is fast, economical, and significantly more sensitive than the conventional test.

\section{References}

1. Friedrich EG. Burch K, and Bahr JP. The vulvar clinic: an eight year appraisal. Am .J (ilnecol 1979:135:1036-40.

2. Capel T, Brown WJ, Jeffries C. Stewart JA. Microbiologic flora of penile ulcerations. I Infect Dis 1978:137:5()-7.

3. Caine VA, Handsfield HH, Corey I. Wang SP. Holmes KK. Prospective study of the aetiology of genital ulcers. Proceedings of the first sexually transmitted discases world congress. San Juan. Puerto Rico: Latin American Union against Venereal Diseases 1981:46-52.

4. Communicable Disease Surveillance Centre. Sexually transmitted diseases surveillance. 1979. Br Mod./ 1981:282:1556.

5. Corey L. Holmes KK. Genital herpes simplex virus intections: current concepts in diagnosis, therapy and prevention. Ann Intern Med 1983:98:973-83.

6. Gardner PS. McQuillan J. Black MM. Richardson J. Rapid diagnosis of herpes simplex virus hominis in superficial lesions by immunofluorescent staining technique. $\mathrm{Br}$ Med Jl 1968:4:8992

7. Chieu Liu, Llaues-Rodas R. Application of immunofluorescent staining technique to the study of pathogenesis and the rapid diagnosis of viral infections. Am I C lin Pathol 1972:57:829-34.

8. Schwartz HS, Vastine DW. Yamashioya H. West CE. Immunofluorescent detection of adenovirus antigen in epidemic keratoconjunctivitis. Investigative ()phthamolog! 1976:15:199-207. 
9. Gordon FB, Harper IA. Quan LA. Treharne JD. Dwyer RStC. Garland JA. Detections of Chlamydia(Bedsonia) in certain infections of man. 1. Laboratory procedures: comparison of yolk sac and cell culture techniques for detection and isolation. J Infect Dis 1969:120:451-62.

10. Jonson GD. Davidson RS. McNamee KC. Goodwin RD. Holborow EJ. Fading of immunofluorescence during microscopy: a study of the phenomenon and its remedy. . Immunol Mcthods 1982:55:231-42.
11. Grist NR. Bell EJ, Follett EAC. Urquhart. GED. Diagnostic methods in clinical virolog:: 3rd ed. Edinburgh: Blackwel Scientific Publications. 1979.

12. Moore DF. Comparison of human fibroblast cells and primary rabbit kidney cells for isolation of herpes simplex virus. J Clin Microbiol 1984:19:548-9.

13. Darougar S. Gibson JA. Thaker U. Effects of centrifugation on herpes simplex virus isolation. I Med Virol 1981:8:231-5. 